\title{
Lab Scale Preparation And Evaluation OF YTTRIA STABILIZED ZIRCONIA THERMAL BARRIER COATINGS AND ITS INFLUENCE ON THE DIESEL ENGine PERFormanCE
}

\author{
Shankar. V ${ }^{1}$, V.R. Reghu ${ }^{2}$, Parvati Ramaswamy ${ }^{3}$ and Kevin Vattappara ${ }^{4}$ \\ ${ }^{1}$ Professor \& Principal Investigator, \\ ${ }^{2}$ Associate Professor and PhD Scholar, \\ ${ }^{3}$ Visiting Research Faculty, \\ ${ }^{4}$ Fellowship - undergraduate final year student \\ Major Research Project -Diesel Engine Research \& Development \\ Surface Engineering Laboratory \\ Department of Mechanical Engineering, Faculty of Engineering, Christ University \\ Bangalore-560074, India \\ ${ }^{1}$ Email: shankar.v@christuniversity.in
}

\begin{abstract}
Ceramic based coatings are routinely being engineered to protect metallic components from high temperature environments in applications like gas turbines and jet engines. However, although a wellresearched technology, detailed and realistic information on the effects of thermal barrier coatings (TBCs) in improving the performance of commercial diesel engines is either classified or inconsistent. Additional information by means of lab scale and analytical evaluation of TBCs prepared from $8 \% \mathrm{Y}_{2} \mathrm{O}_{3}-\mathrm{ZrO}_{2}$ plasma sprayable powders (prepared in the laboratory by using organic binders), coated onto aluminium substrates, corroborated by simulation model is one part of this paper. The findings are supplemented by studying the influence of the TBCs on aluminium pistons in a single cylinder nine horsepower class diesel engine, thereby carrying out realistic performance of the engine involving parameters such as Power (Brake, Indicated and Frictional), thermal efficiency, fuel consumption, effects of ceramic insulation on emission and exhaust temperature and peak cylinder pressure, as the concluding part of the studies.
\end{abstract}

\section{KEYWORDS}

$\mathrm{Y}_{2} \mathrm{O}_{3}$-stabilized Zirconia plasma sprayed TBCs, TBC coated piston, diesel engine performance, simulation model of TBCs on aluminium substrate.

\section{BACKGROUND INFORMATION}

At the Mechanical Engineering Department, Faculty of Engineering Christ University, Bangalore, one of the major research focuses is on diesel engine. Based on the submission of a research proposal [1] and under the Major Research Project (MRP) scheme, an in-house funded project has been sanctioned [2] during November 2013 by the Centre of Research Projects, Christ University for a period of three years. The aim and objective in three phases is a) to create a state-of-the-art facility catering to various class of diesel engines in the range of five to 
hundred HP. Five to ten HP single cylinder engines are used for irrigation and tiller applications whereas sixty to eighty HP class four cylinder engines are used for light motor vehicle applications, b) to evaluate the base line engine characteristics by extensive testing and endurance testing and c) to work on engine modification by going in for Low Heat Rejection (LHR) engine with the idea of providing value added inputs on the existing engine in terms of better Specific Fuel Consumption (SFC) and reduced pollutants. Research work is in good progress and LHR engine is realized by Thermal Barrier Coating (TBC) of piston crown. Before coating on the actual piston, coating trials are in progress on fabricated research piston and tested for thermal barrier and thermal shock in in-house developed laboratory scale burner rig facility at the Surface Engineering Laboratory. Coatings also would be tested for adherence before implementing on the piston crown. About a dozen thrust areas are identified. Over half a dozen research faculties from various departments - Mechanical, Electrical, Electronics, Mathematics and Chemistry departments participate in this interdisciplinary research program and thirty undergraduate research students participate in the program. The potential includes: a) faculty pursuing Ph.D b) Students performing research after prescribed academic hours and turning out project/fellowship reports and c) vendor development for associating with research work. While Amado Tools, Bangalore is involved in fabrication related activities and Spraymet industries, Bangalore is involved in plasma spraying on specimen, Central Manufacturing Technology Institute (CMTI), Bangalore is involved in material characterization and Tech Ed Industries is involved in establishing and maintenance of diesel engine test rigs and laboratory burner rig .

\section{INTRODUCTION}

The technology and advantages of thermal barrier coatings (TBCs) on the hotter side of diesel or turbine engine components, although are well-established and accepted, the adaptability of these ceramics in different applications are still being pursued actively. Ceramic coatings are being considered for diesel engine cylinder liners, piston caps, valve faces and seats, piston rings, and other parts and for turbine components such as combustors, blades, stators, seals, and bearings. TBC's have been used to simulate adiabatic engines with the intention not only for reduced incylinder heat rejection and thermal fatigue protection of underlying metallic surfaces, but also for possible reduction of engine emissions [3 to 5]. The operating efficiency of propulsion and power generation devices (such as diesel engines, gas turbines and jet engines) increases with their operating temperature [6].

The application of TBC's are expected to reduce the heat transfer to the engine cooling jacket through the combustion chamber surfaces (which include the cylinder head, liner and piston crown) and piston rings. The insulation of the combustion chamber with this coating, which is mainly ceramic based, influences the combustion process and hence the performance and exhaust emission characteristics of the engines. The former is easily understood from the first law of Thermodynamics, although the reduction in cylinder heat rejection may not favourably convert into a useful mechanical work but rather as an increased waste heat in the engine exhaust. The latter is extremely complicated because the increased air (or fuel-air mixture) temperature, due to the TBC (before the onset of combustion), could alter the ignition characteristic of the fuel-air mixture and its subsequent reaction mechanism, which are directly related to the exhaust emission characteristics. Moreover, the thermo physical properties of the coated ceramic and its surface roughness and pore characteristics (Number and Size), have a direct influence on un-burnt or partially burnt hydrocarbons through the surface quenching effect and their residence in the pores. 
The desire to increase thermal efficiency or reduce fuel consumption of engines makes it attractive to adopt higher compression ratios, in particular for diesel engines and reduced incylinder heat rejection. Both these factors lead to an increase in mechanical and thermal stresses. The durability concerns for the materials and components in the engine cylinders, which include piston, rings, liner and cylinder head, limit the allowable in-cylinder temperatures [7]. Application of TBC's to the surfaces of these components enhances high temperature durability by reducing the heat transfer and lowering temperatures of the underlying metal.

Reductions in heat transfer, improvement in thermal efficiency, and increase in energy availability in the exhaust system have been observed by many researchers [8 to 13]. However, expectations differing from the above concepts have also been noted [14] by involving the use of ceramic materials as TBC's in practical applications. Partially/Fully Stabilized Zirconia (PSZ/FSZ) has excellent toughness, hot strength and thermal shock resistance, low thermal conductivity and a thermal expansion coefficient close to those of steel and cast iron. PSZ has been widely used as a TBC in the combustion of diesel engines $[15,16]$. The applicability of TBC to Spark Ignition (SI) engine and Compression Ignition (CI) Engine is discussed in the paper by Sivakumar and Shankar [17]. Hari [18] discusses the effect of TBC on eleven HP class engine. Kevin Vattappara [19] discusses yttria stabilized zirconia as TBC on metal substrates. Reghu [20] discusses TBC development on piston crown and simulation of LHR engines.

\section{Scope Of The Present Investigation}

The present investigation focuses on rectangular substrates. 300 micron thick TBCs were prepared on 50 micron thick Nickel Aluminide (NiAl) bond coated aluminium substrates. The TBCs were prepared from $8 \% \mathrm{Y}_{2} \mathrm{O}_{3}-\mathrm{ZrO}_{2}$ plasma sprayable powders (prepared in the laboratory by using organic binders), coated onto $3 \mathrm{~mm}$ thick aluminium substrates, and subjected to thermal shock cycles and evaluated for number of heat quench cycles and thermal barrier characteristics. Both the tests were carried out by using a Surface Engineering Laboratory- designed and developed simulated burner rig facility.

\subsection{Simulation Model Involving TBCS}

The prime role of a TBC is to introduce a temperature drop across the thickness of the coating by the merit of the thermal insulation characteristics it possesses. In addition to the thermal conductivity, the other contributing characteristics are the (a) Coating Thickness (b) Coating Surface Temperature (c) Coating and Substrate Specific Heat (d) Density and finally (e) the Ambient Environment Conditions.

These parameters were used to simulate a model in order to be able to predict the ability of the coatings to function as TBC's as well as their efficiency in terms of temperature drop across the coating.

The model of the TBC coated substrate was prepared using Solid Edge V18 platform. Then the model was imported into Hypermesh 13.0 and meshed with each zone being done separately. Then the meshed model was imported to Ansys Fluent 14.5, where the model was given its material properties and it was simulated for different temperatures (varying from $250^{\circ} \mathrm{C}$ up to $650^{\circ} \mathrm{C}$, at regular $\Delta \mathrm{T}$ of $\sim 100$ degrees). A suitable ambient temperature higher than room temperature was incorporated in the model which varied with each rise in temperature. 


\subsection{Thermal Barrier and Thermal Shock Tests}

The thermal barrier test involved exposing the ceramic coated surface with a high temperature flame focused on the centre of the coated specimen, allowing the ceramic surface sufficient time ( 2 hours) to attain the intended stabilized temperature under the steady flame conditions (flame temperatures (T) varying from 250 up to $650^{\circ} \mathrm{C}$, (melting point of Aluminium: $660^{\circ} \mathrm{C}$ ) at regular $\Delta \mathrm{T}$ of $\sim 100$ degrees). The substrate temperature at the back of the specimen was measured to an accuracy of \pm 5 degrees.

The thermal shock test involved exposing the ceramic surface to $650^{\circ} \mathrm{C}$ for a pre-fixed amount of time (5 minutes) and suddenly withdrawing the specimen to face a blast of cold air to rapidly quench the hot ceramic surface including the aluminium substrate; thereafter reintroducing the ceramic surface to the flame after five minutes hold at the relatively colder ambient. The numbers of such heat quench cycles were recorded to assess the suitability of the TBC to protect the aluminium substrate from such an extremely harsh thermal environment. Figure.1 shows the test facility.

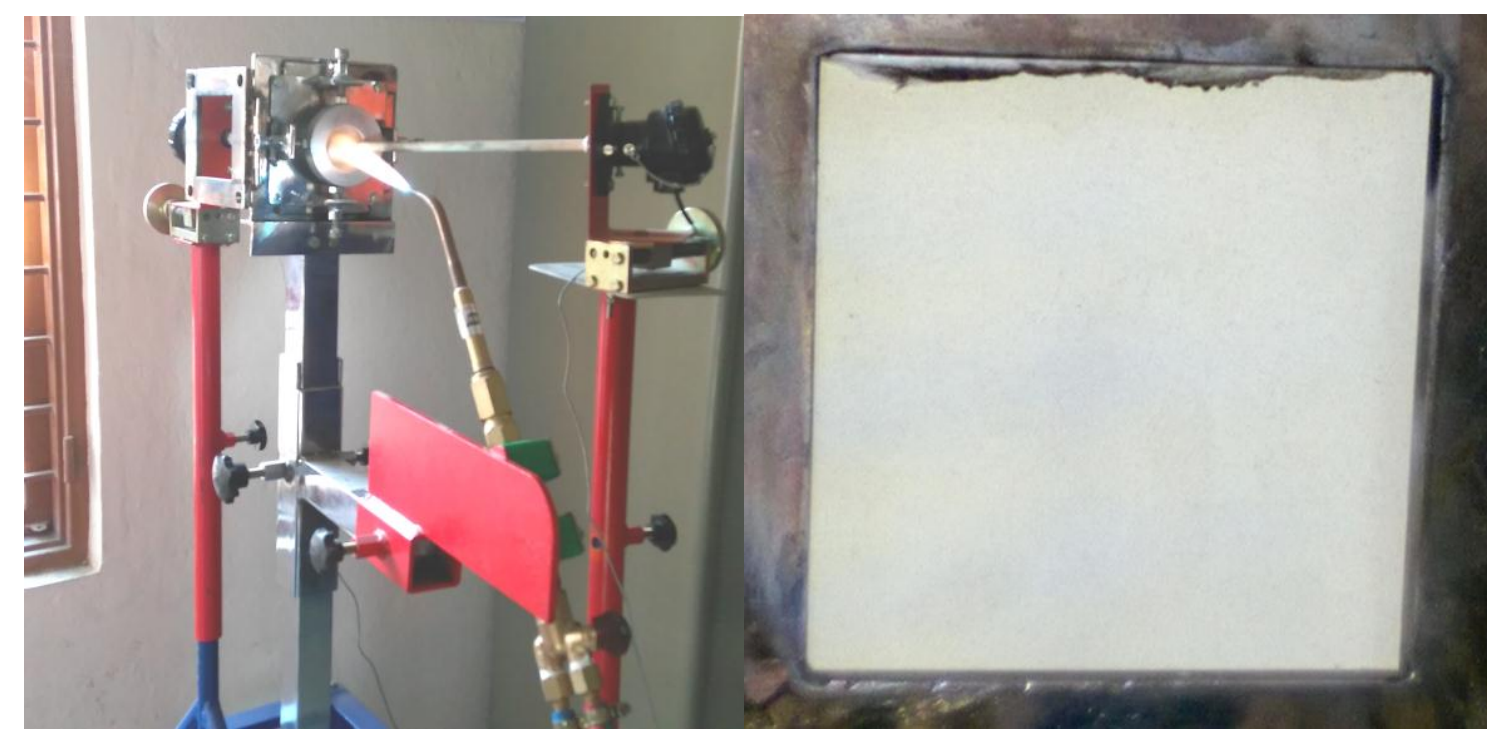

Fig.1. Simulated Burner Rig Test Facility at FECU with a typical Thermal Barrier Coated substrate mounted on test set-up.

\subsection{Effect of Insulation on Engine Performance (Engine test)}

Once having established the suitability of the laboratory prepared plasma sprayable powder to function as TBCs possessing technologically sound characteristics, the same technology of powder and coating preparation was employed to prepare Thermal Barrier Coated pistons. The regular piston of the diesel engine was replaced with TBC $(300 \mu \mathrm{m})$ coated piston and the engine was coupled with dynamometer of test facility. A schematic of the the diesel engine R \& D test facility is shown in Fig. 2. 


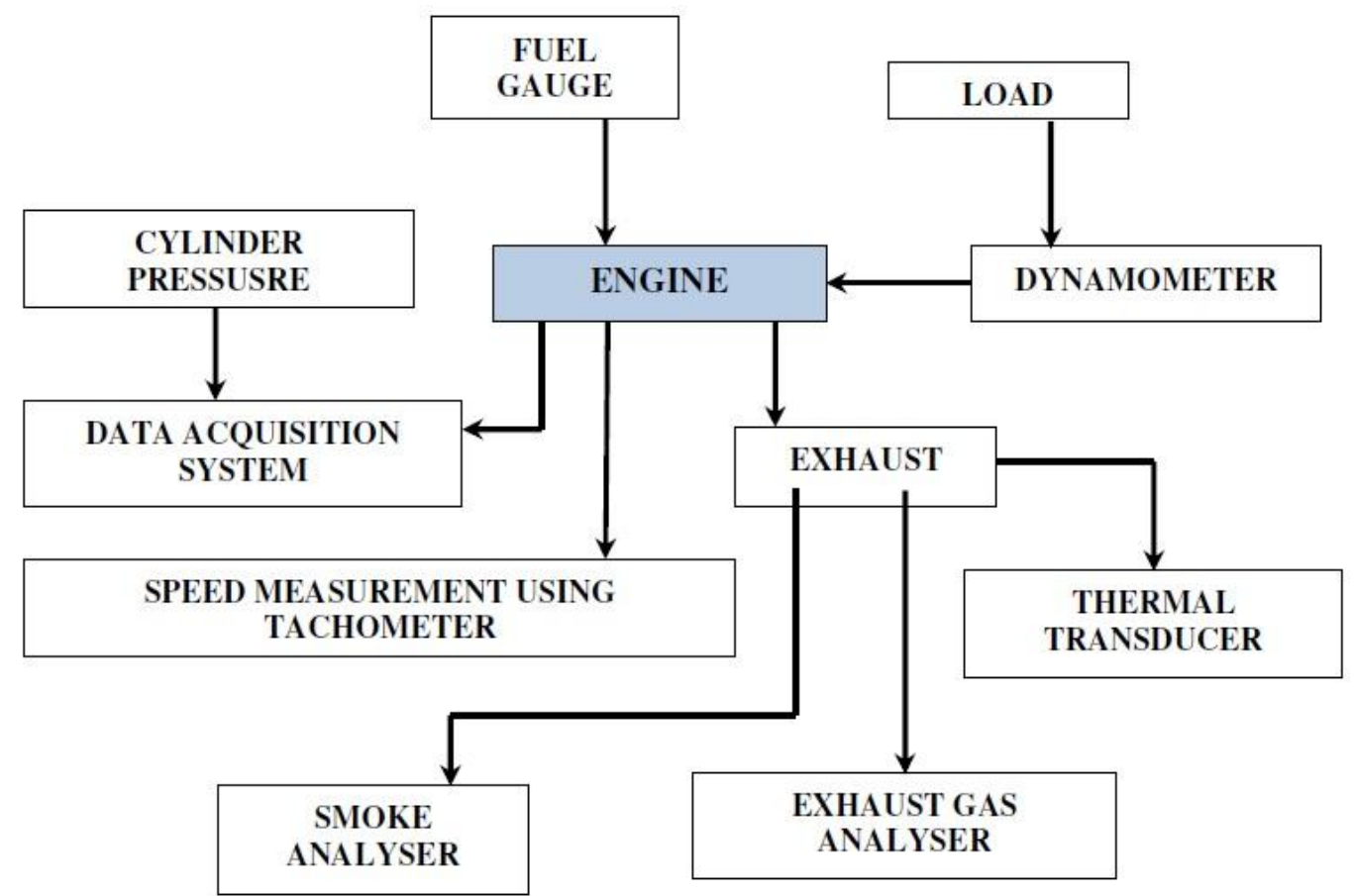

Fig.2. Schematic of the Engine test facility

3.3.1. The following characteristics were evaluated for the engine with TBC and compared with the data obtained from the same engine with uncoated piston

a) Power (Brake, Indicated and Frictional),

b) Thermal efficiency,

c) Fuel consumption,

d) Emission

e) Exhaust temperature and

f) Peak cylinder pressure.

g)

The main emphasis has been on investigating the effect of a TBC on the engine fuel consumption, emission measurements of unburned hydrocarbons and carbon monoxide. The LHR engine has been conceived basically to improve fuel economy by minimising the heat loss to the surroundings. In the present work, an attempt is made to review the previous studies to look into future possibilities of the LHR engine from the view point of combustion, heat transfer and emission by application of TBC.

\section{SALIENT FindingS}

\subsection{Simulation Model Involving TBCS}

4.1.1 Fig.4 shows a snapshot of a part of the model developed for the TBC on aluminium substrate with 300 micron thick coating on 50 micron thick Nickel Aluminide (NiAl) bond coat using Solid Edge V18® simulation software. 
International Journal of Recent advances in Mechanical Engineering (IJMECH) Vol.5, No.2, May 2016

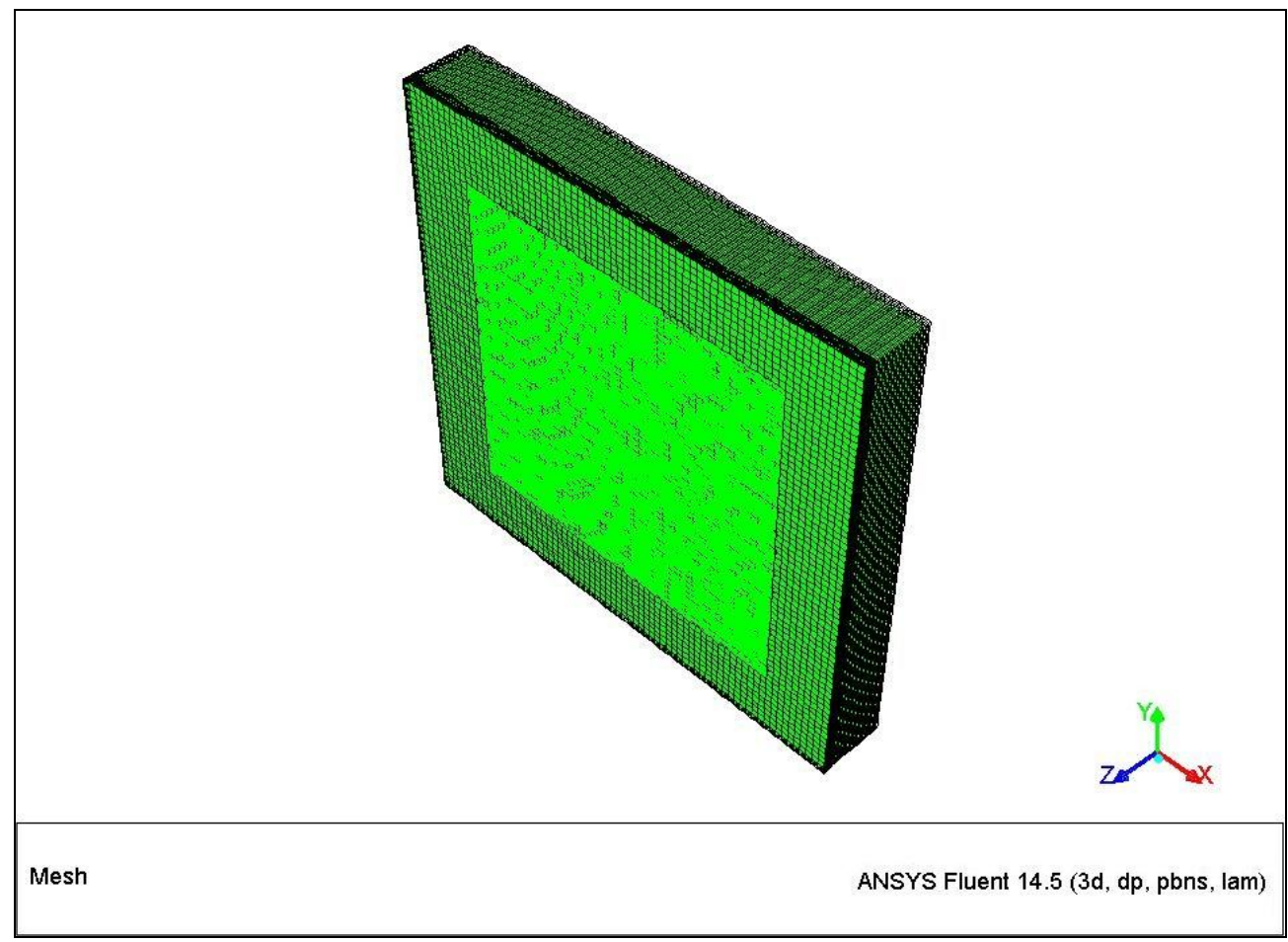

Fig.4: Snapshot of a part of the model developed

4.1.2 Fig.5 (a thru e) shows the temperature contours showing the $\Delta \mathrm{T}$ across the thickness of the $\mathrm{TBC}$, bond coat and substrate.

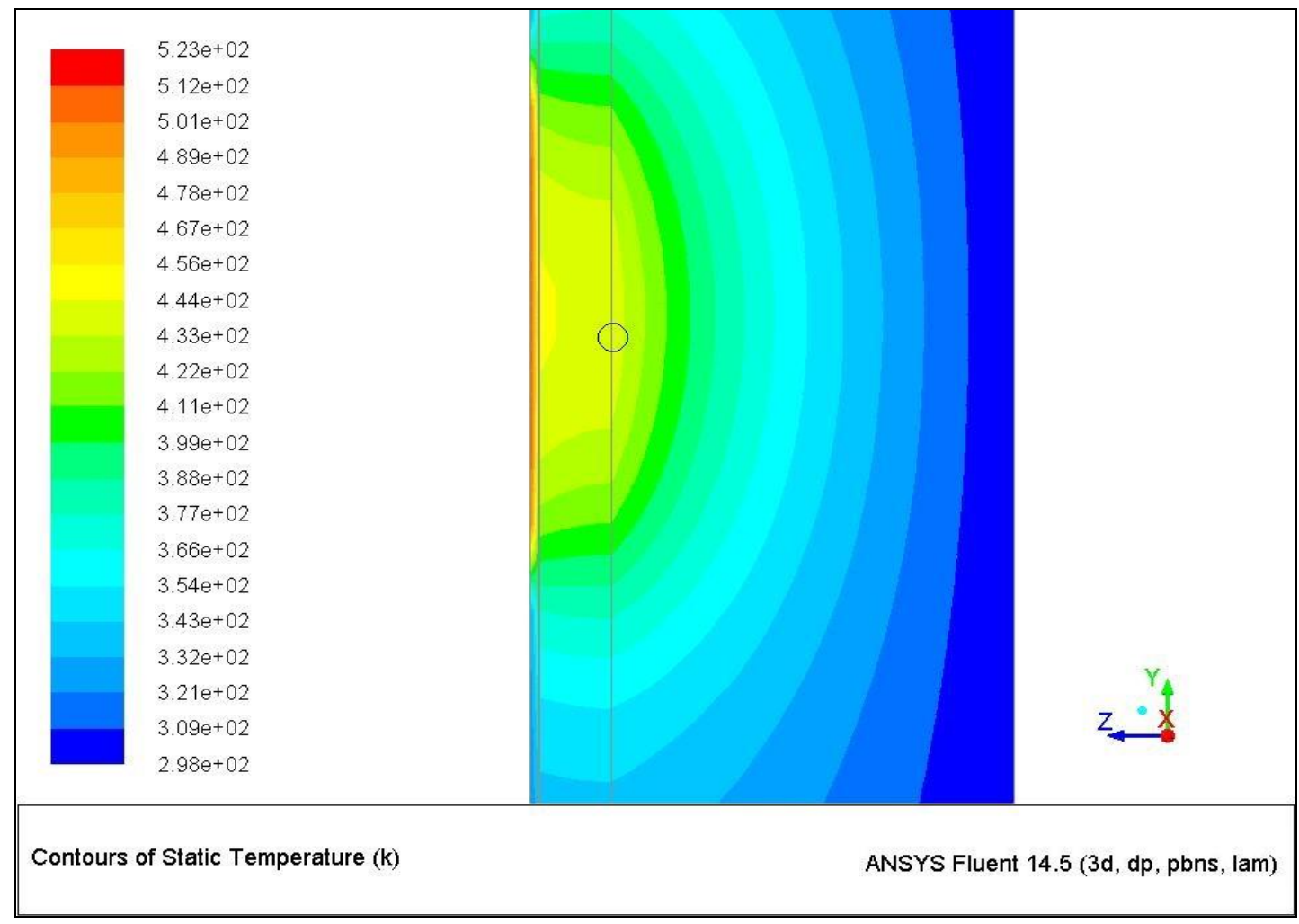

(a) Temperature Contour for $250^{\circ} \mathrm{C}(523 \mathrm{~K})$ 
International Journal of Recent advances in Mechanical Engineering (IJMECH) Vol.5, No.2, May 2016

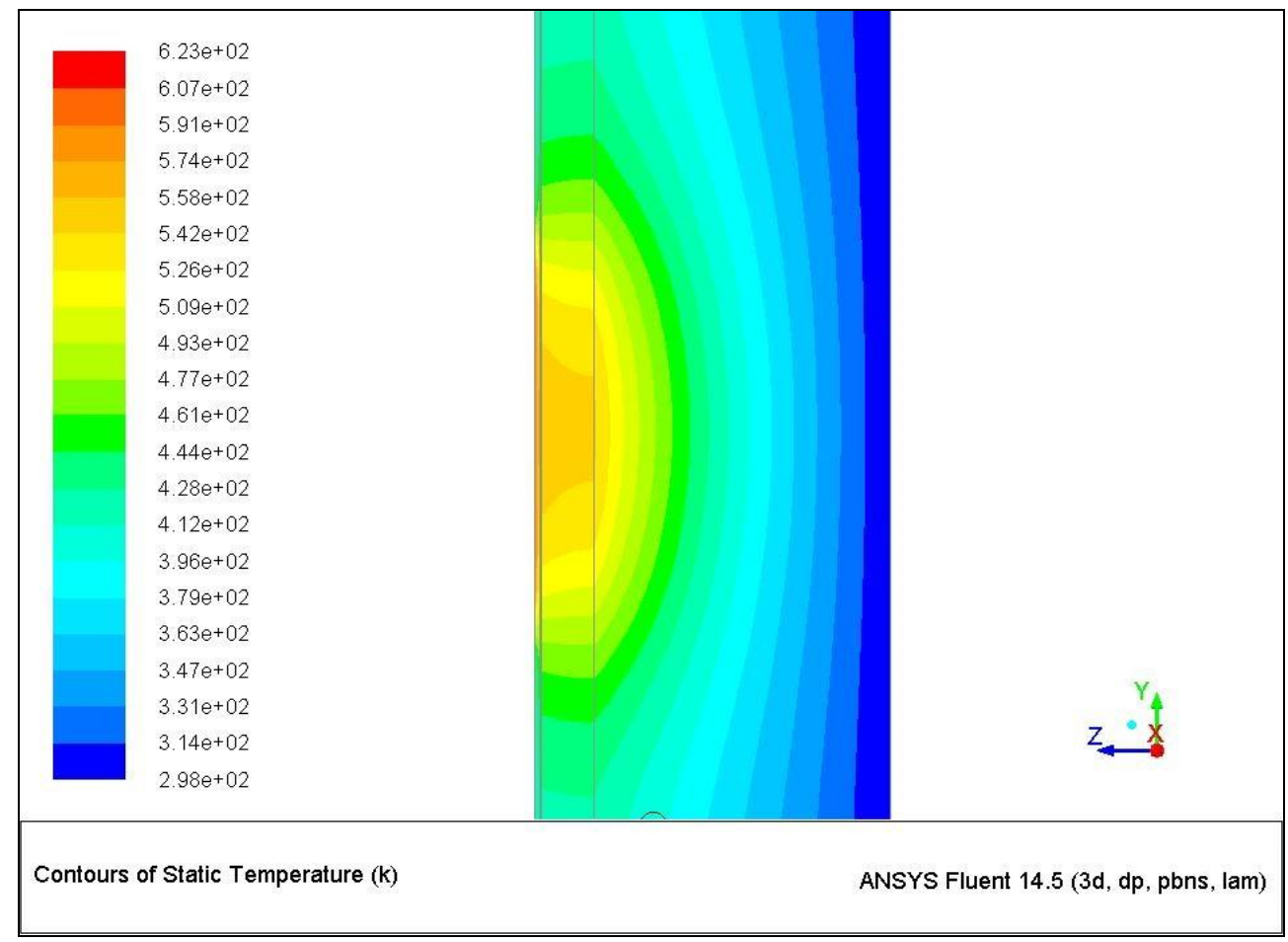

(b) Temperature Contour for $350^{\circ} \mathrm{C}(623 \mathrm{~K})$

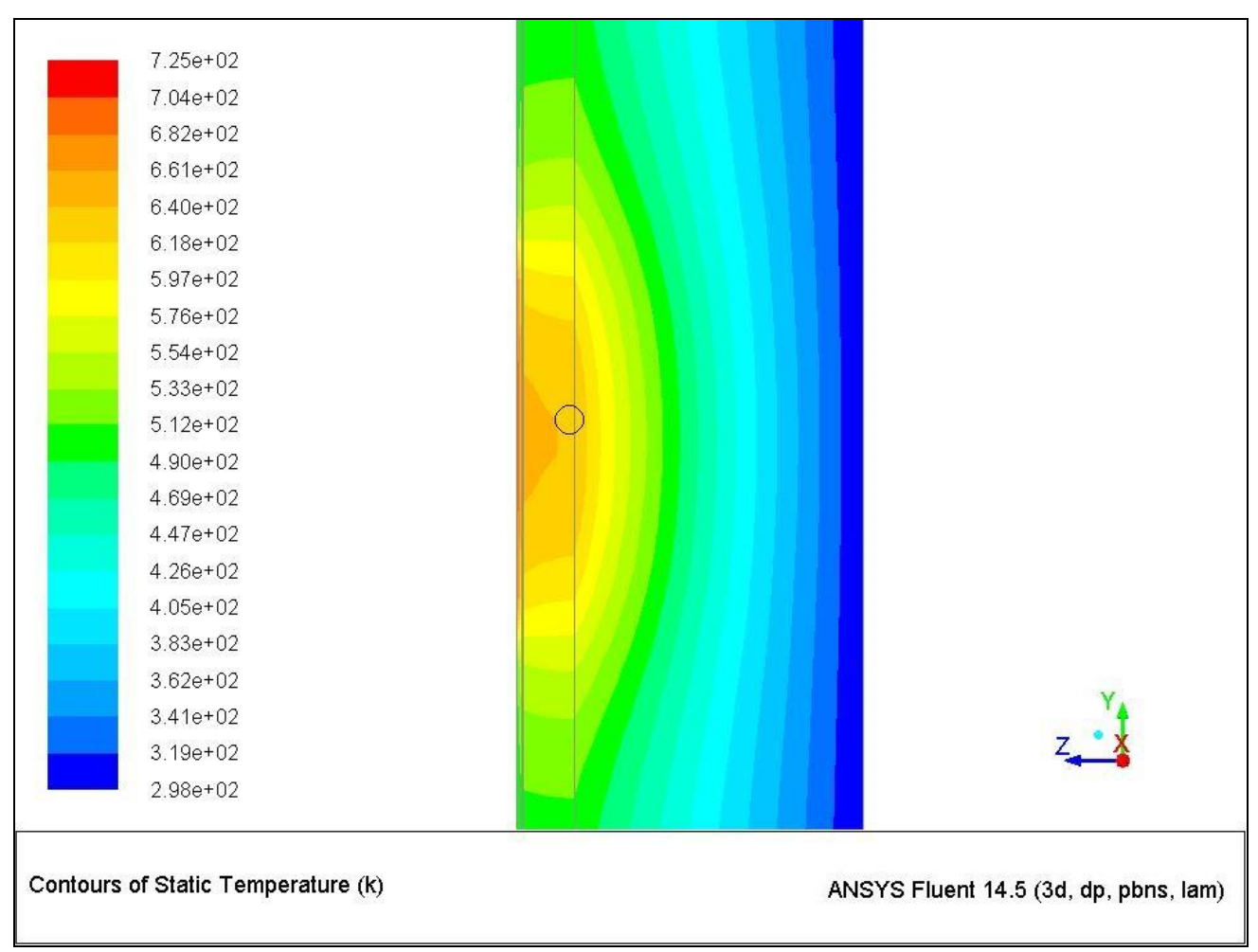

(c) Temperature Contour for $450^{\circ} \mathrm{C}(723 \mathrm{~K})$ 
International Journal of Recent advances in Mechanical Engineering (IJMECH) Vol.5, No.2, May 2016

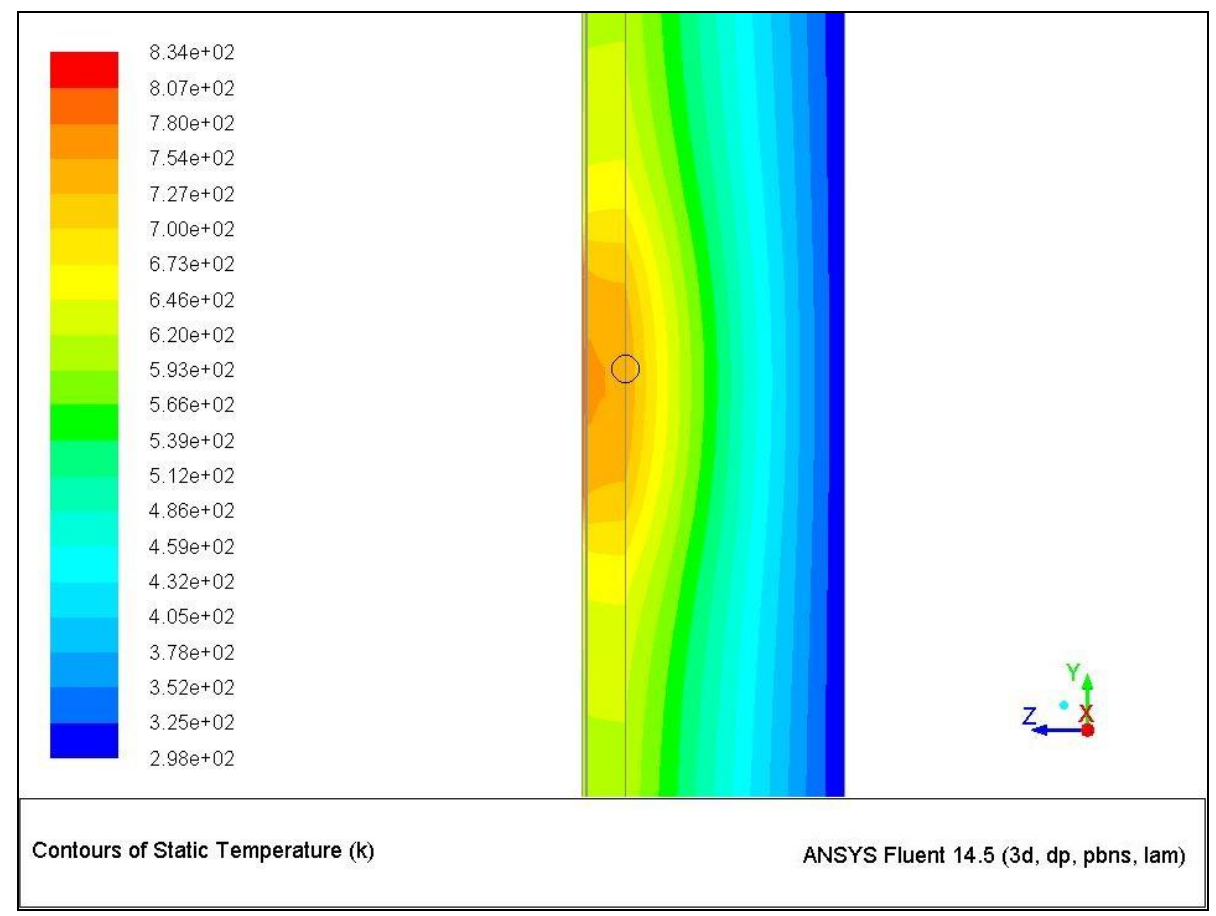

(d) Temperature Contour for $550^{\circ} \mathrm{C}(823 \mathrm{~K})$

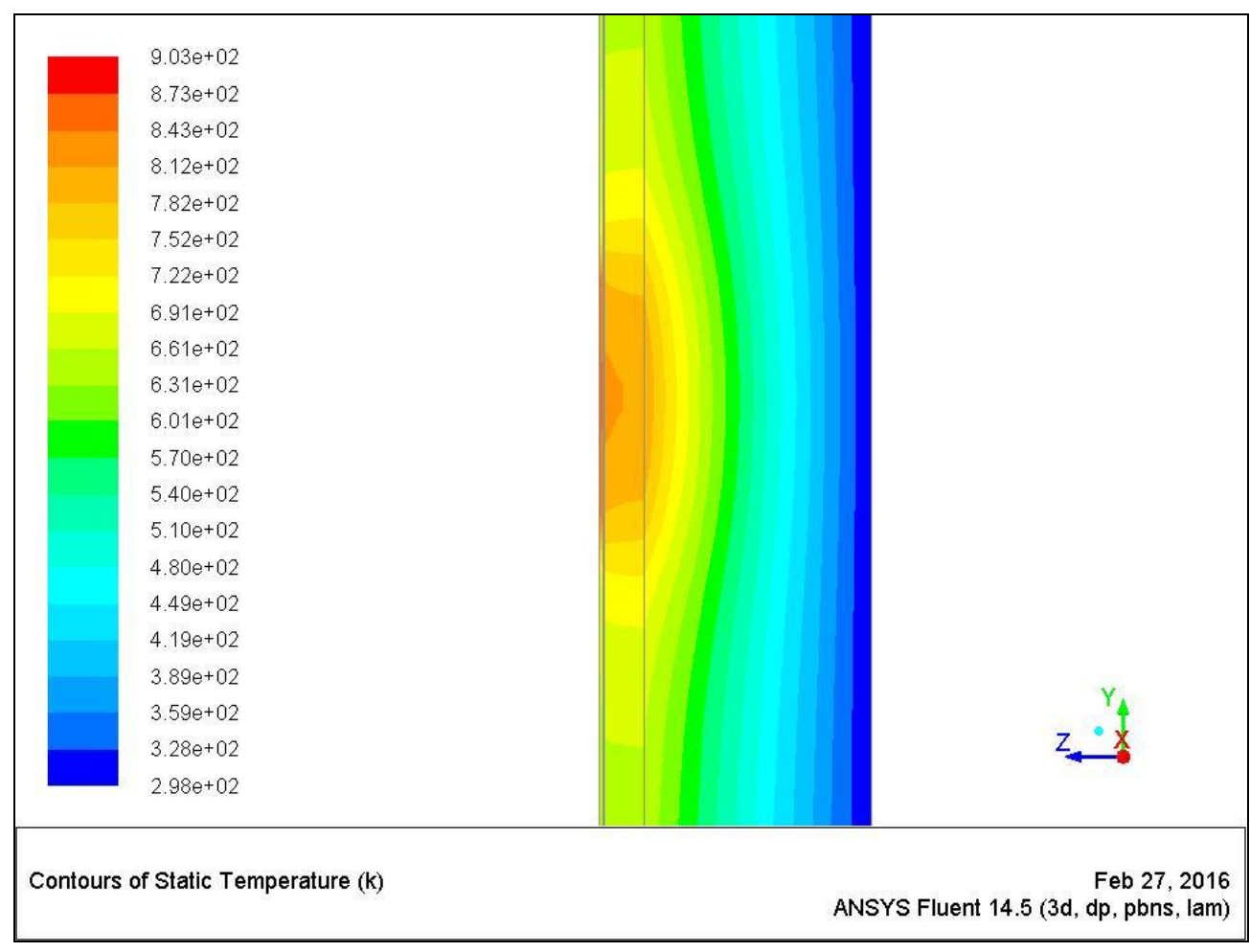

(e) Temperature Contour for $630^{\circ} \mathrm{C}(903 \mathrm{~K})$

Fig.5 (a thru e): Temperature Contours showing the $\Delta \mathrm{T}$ across the thickness of the TBC, bond coat and the substrate. 
International Journal of Recent advances in Mechanical Engineering (IJMECH) Vol.5, No.2, May 2016

4.1.3 Fig.6 (a thru e) shows the graphs pertaining to the temperature contours of the $\Delta \mathrm{T}$ across the thickness of the TBC, bond coat and substrate, shown in Fig.5 (a thru e).

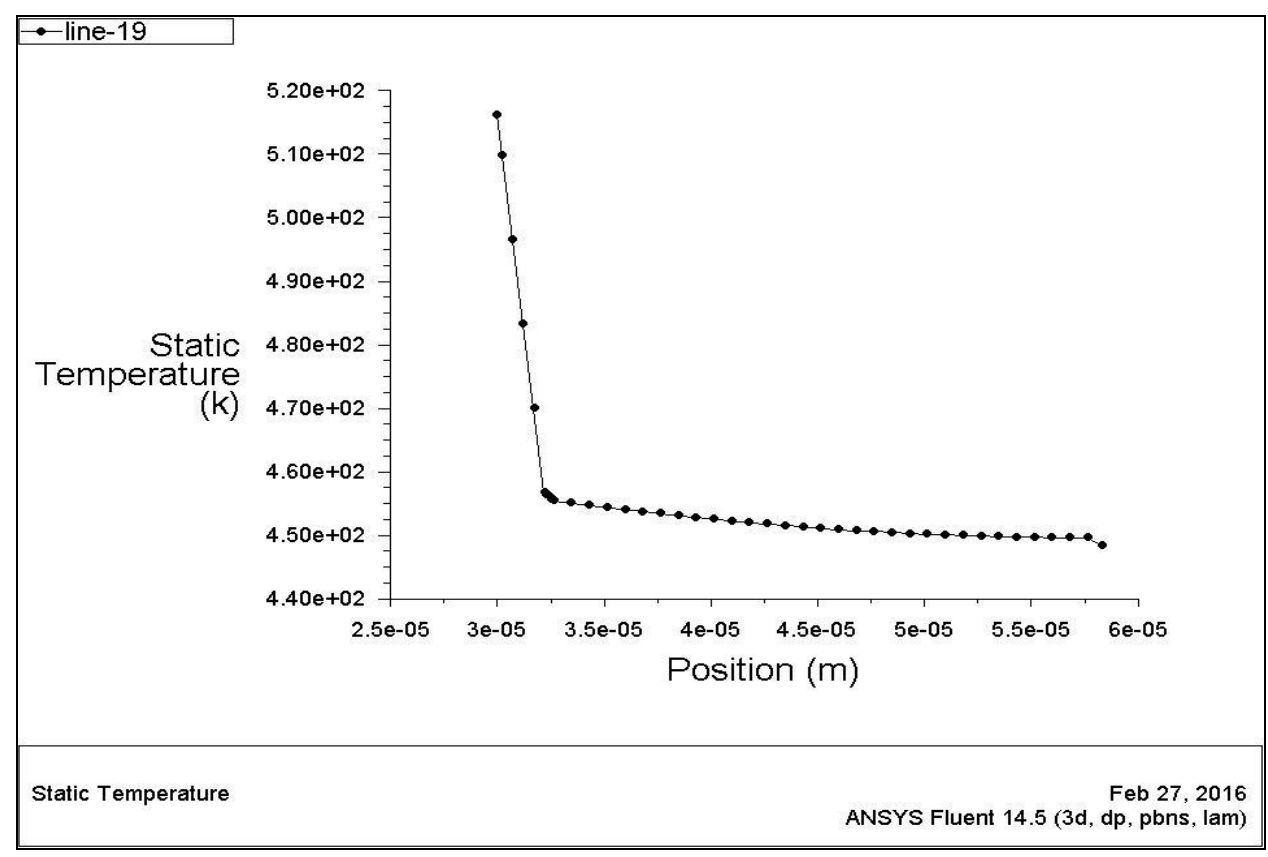

(a) Graph for $250^{\circ} \mathrm{C}(523 \mathrm{~K})$

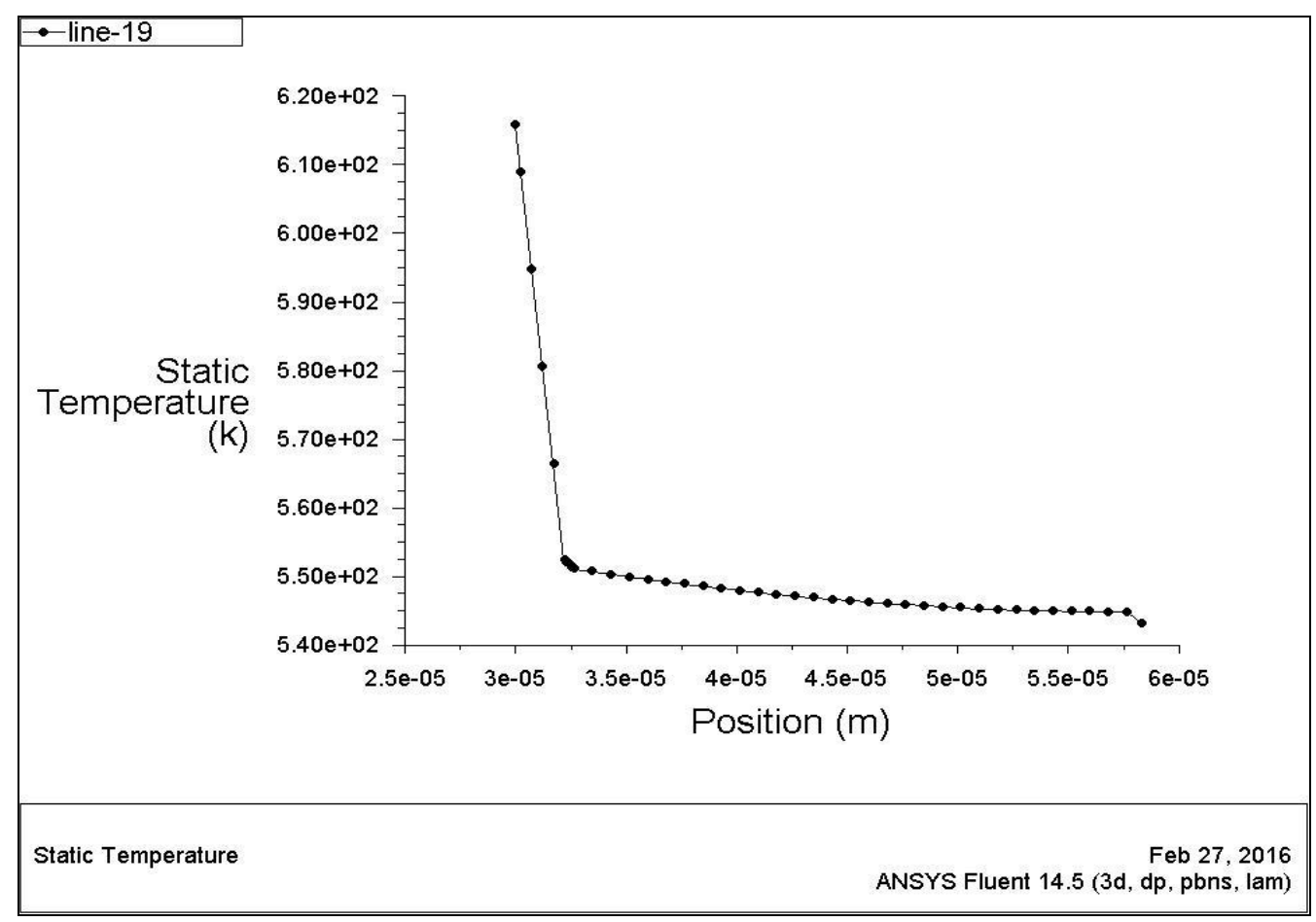

(b) Graph for $350^{\circ} \mathrm{C}(623 \mathrm{~K})$ 
International Journal of Recent advances in Mechanical Engineering (IJMECH) Vol.5, No.2, May 2016

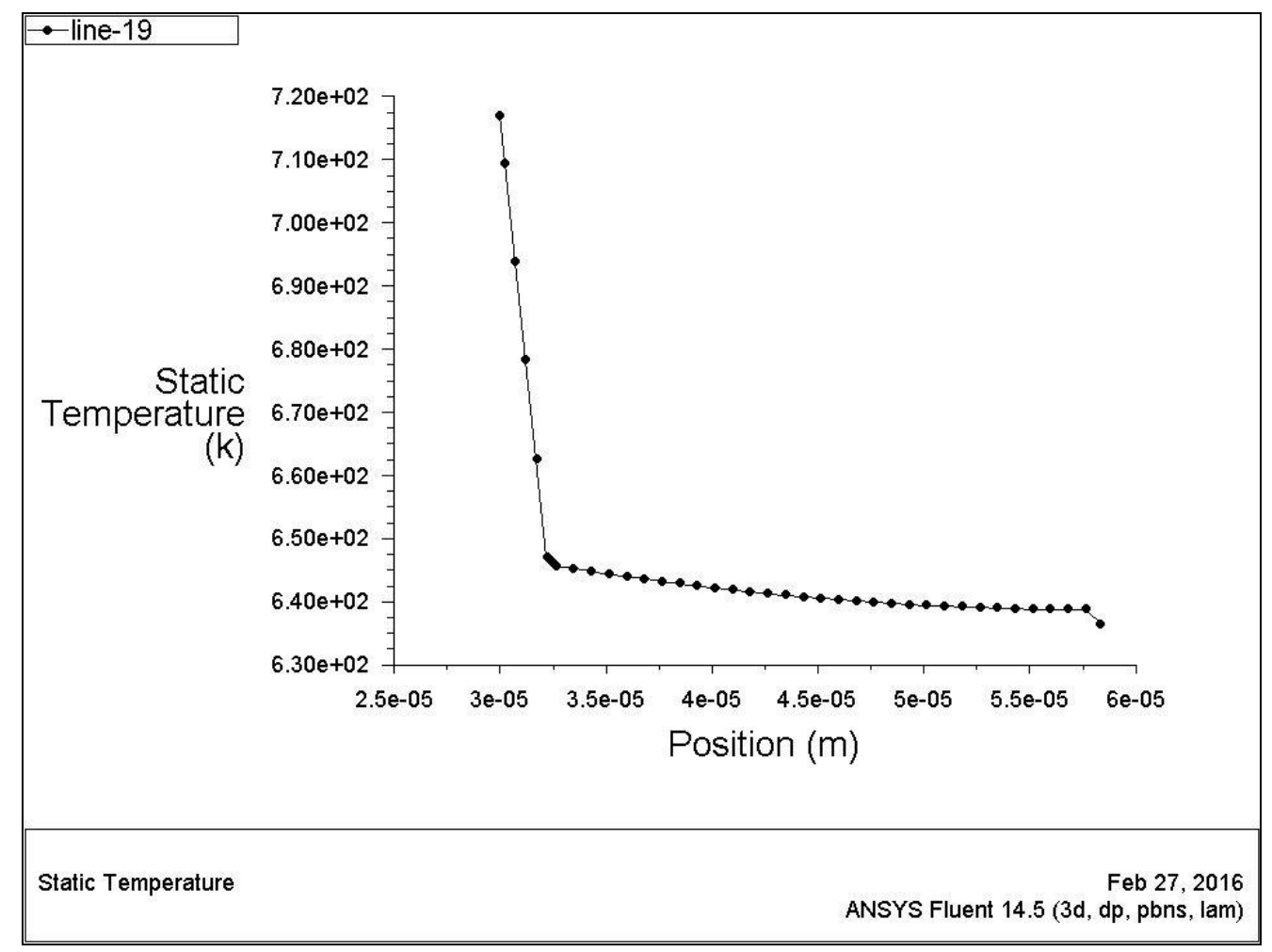

(c) Graph for $450^{\circ} \mathrm{C}(723 \mathrm{~K})$

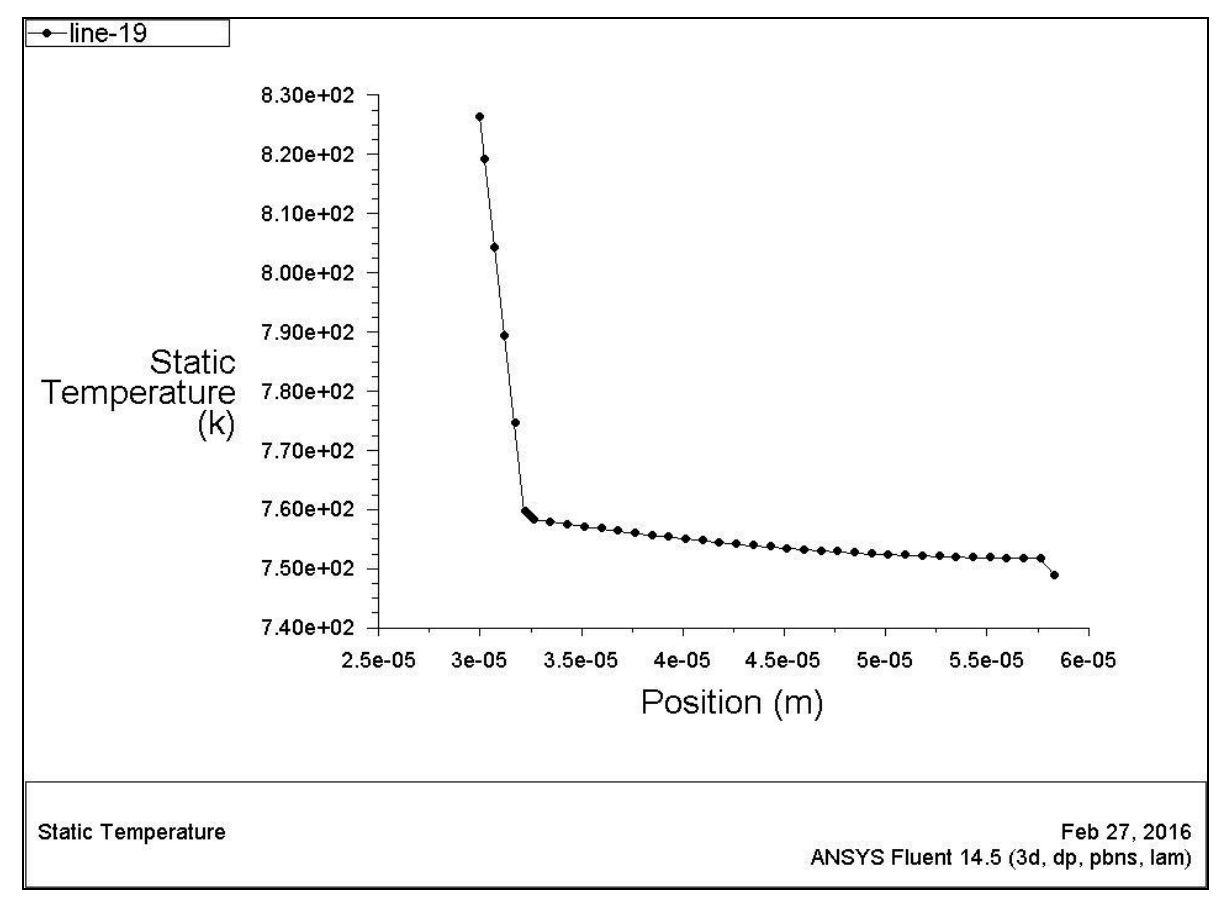

(d) Graph for $550^{\circ} \mathrm{C}(823 \mathrm{~K})$ 
International Journal of Recent advances in Mechanical Engineering (IJMECH) Vol.5, No.2, May 2016

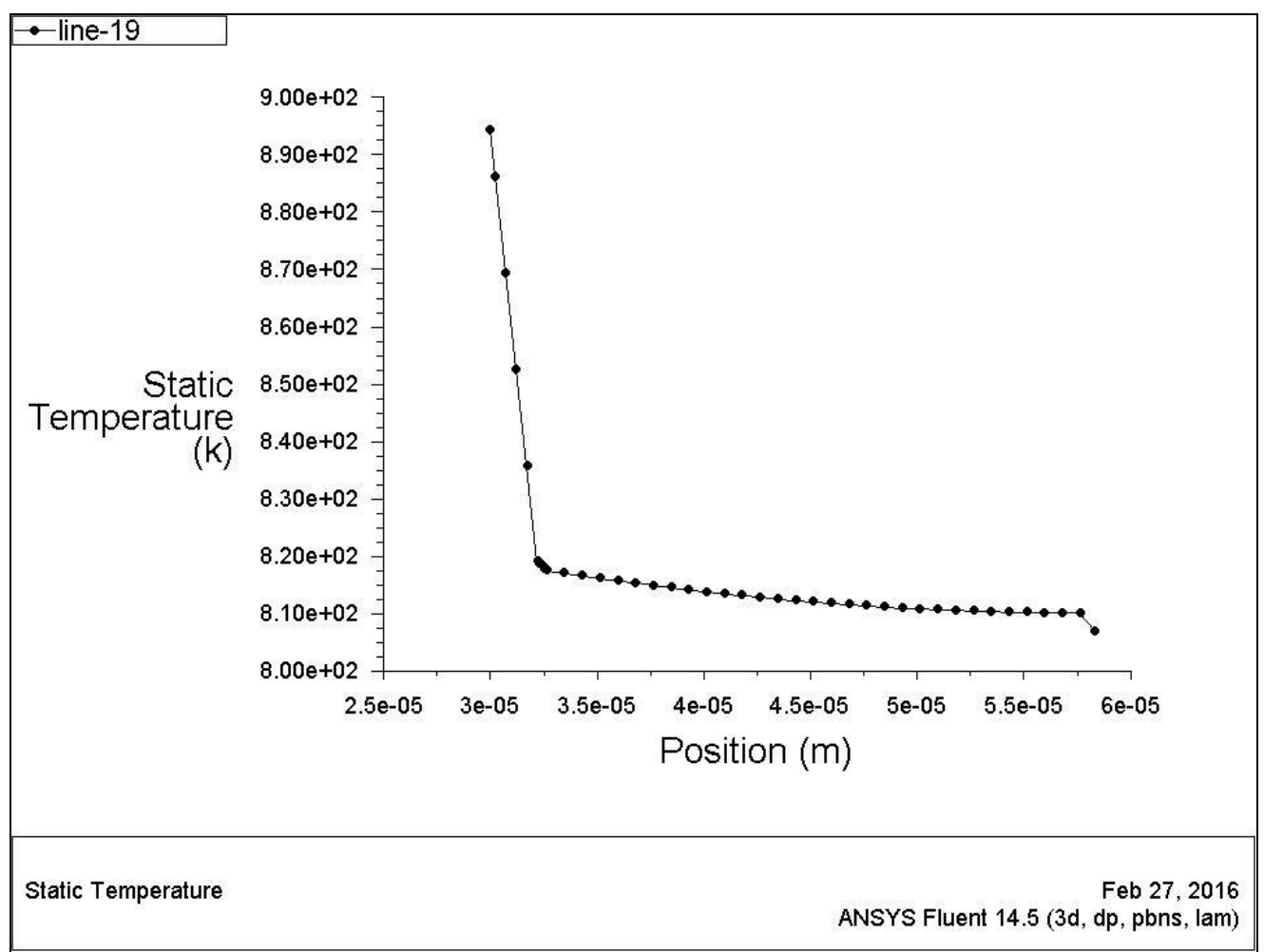

(e) Graph for $630^{\circ} \mathrm{C}(903 \mathrm{~K})$

Fig.6 (a thru e): Graphs pertaining to temperature contours showing the $\Delta \mathrm{T}$ across the thickness of the TBC, bond coat and substrate.

\subsection{Thermal Barrier and Thermal Shock tests}

\subsubsection{Thermal Barrier Test}

Fig.7 shows the test results of the thermal barrier tests described in section 3.2 and Fig.1.

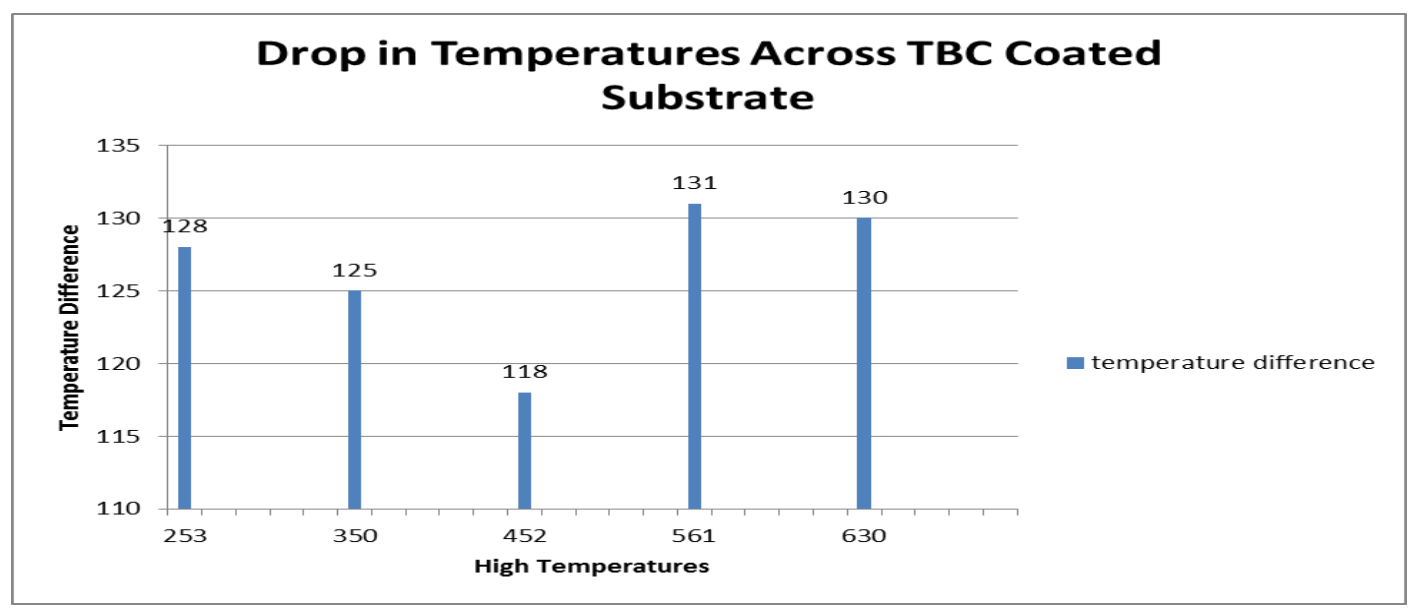

Figure7. Thermal barrier test results -Temp (C) 


\subsubsection{Thermal Shock Test}

The TBC, described in the previous section was subjected to more than 500 heat - quench cycles before the test was stopped. Visual inspection revealed no degradation or cracking of the top coat and no detachment from the substrate.

\subsection{Effect of Insulation on Engine Performance}

Fig. 8 shows the photograph of a typical TBC coated piston of about $80 \mathrm{~mm}$ in diameter that is incorporated into the single cylinder engine and subsequently tested for its performance.

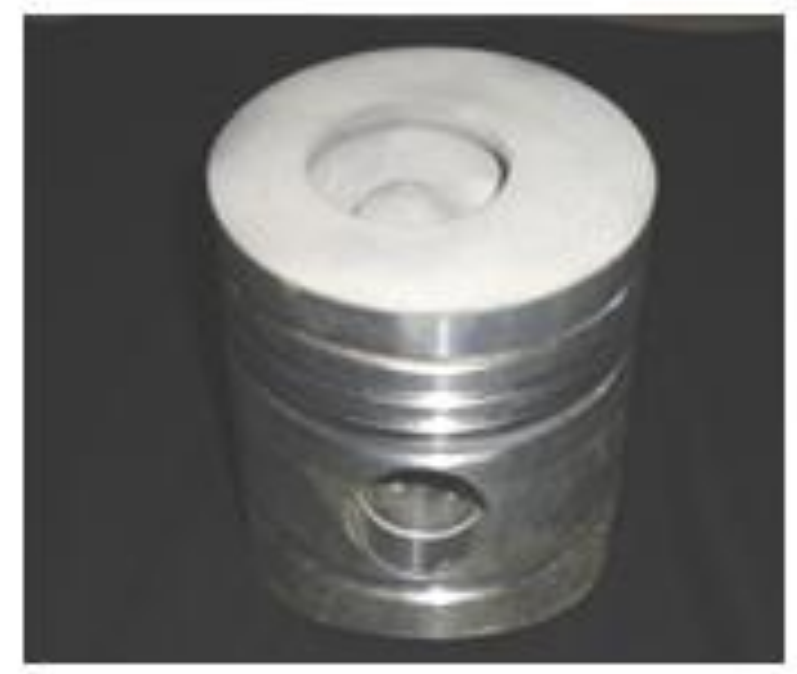

Fig. 8 Typical TBC Coated Piston

\subsubsection{Highlights Of Experimental Results}

Highlights of the experimental results are presented and discussed.

\section{(a) Brake Thermal Efficiency}

Thermal efficiency is true indicator of the efficiency with which the chemical energy input in the form of fuel is converted into useful work. Improvement in engine thermal efficiency by reduction of in-cylinder heat transfer is the key objective of engine research. The brake thermal efficiency is marginally higher in the engine with ceramic coated piston (TBC) when tested for the same opearting condition, with an improvement of up to $2.31 \%$ at higher load. In-cylinder heat transfer characteristics of engine are still not clealy understood. Fig. 9 gives the trend of brake mean effective pressure vs thermal efficiency. Efficiency increase in the engine with the coated piston could be clearly seen (as shown in Fig 9). 


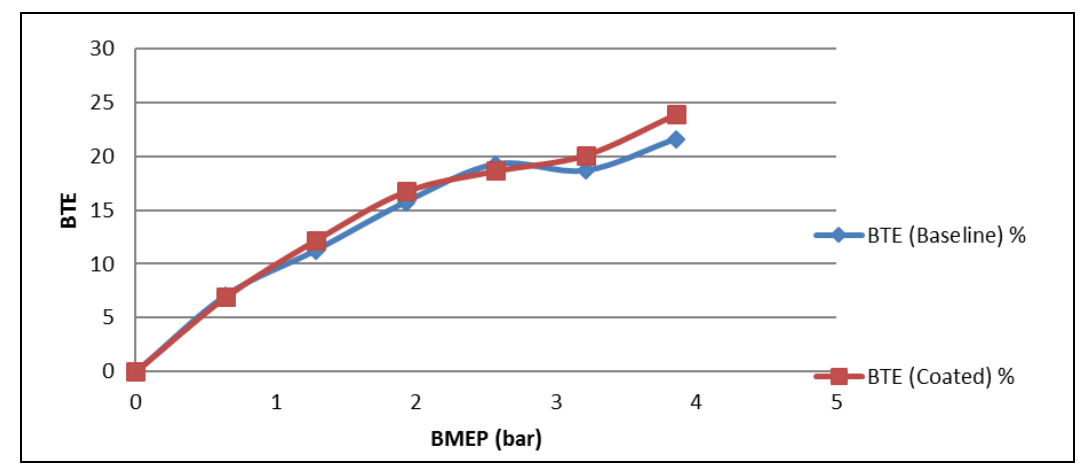

Fig. 9 Brake Mean Effective Pressure vs Brake Thermal Efficiency

\section{(b) Fuel Consumption}

Fig. 10 indicates the brake power vs fuel consumption. The results indicate the reduction in fuel consumption in the engine with ceramic (TBC) coated piston. The level of reduction has been in the range of $1.5 \%$ with a maximum of $9.6 \%$ seen at the maximum Brake Power. Idling of the engine with coated piston at no load for longer duration is expected to reduce the fuel consumption at minimum BP.

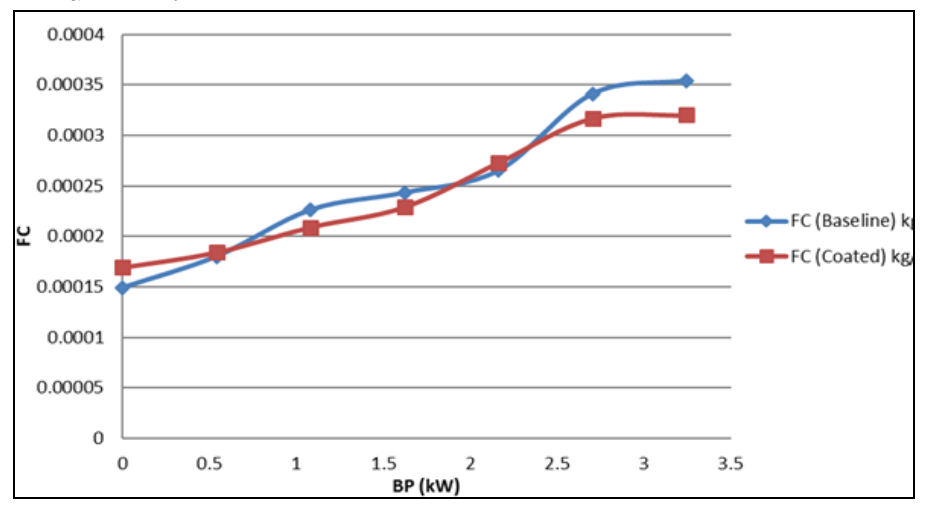

Fig. 10 Brake Power vs Fuel Consumption

The trend of reduced fuel consumption with insulating coating (TBC) on the piston is readily established by this experiment and the influence of TBCs on piston crown as an effective means of reducing heat rejection and hence reducing fuel consumption is also observed.

\section{(c) Effect Of Insulation On Emissions}

The effects of insulation on emission characteristics of the engine are detailed below.

\section{UBHC ( UNBURNT HYDROCARBON)}

The emission of UBHC from the engines is more likely to be reduced because of the decreased quenching distance and the increased lean flammability limit. The higher temperatures both in the gases and at the combustion chamber walls of the LHR engine assist in permitting the oxidatioin reactions to proceed close to completion. In some cases there has been an increased level of UBHC emissions. This is possibily attributed to deterioation in diffusion combustion. The burning of lubricating oil due to high wall temperature is believed to be the other reason for increased UBHC level. The present investigations show that UBHC level is increased in general and reduced at higher load and this trend is shown in Fig. 11. 


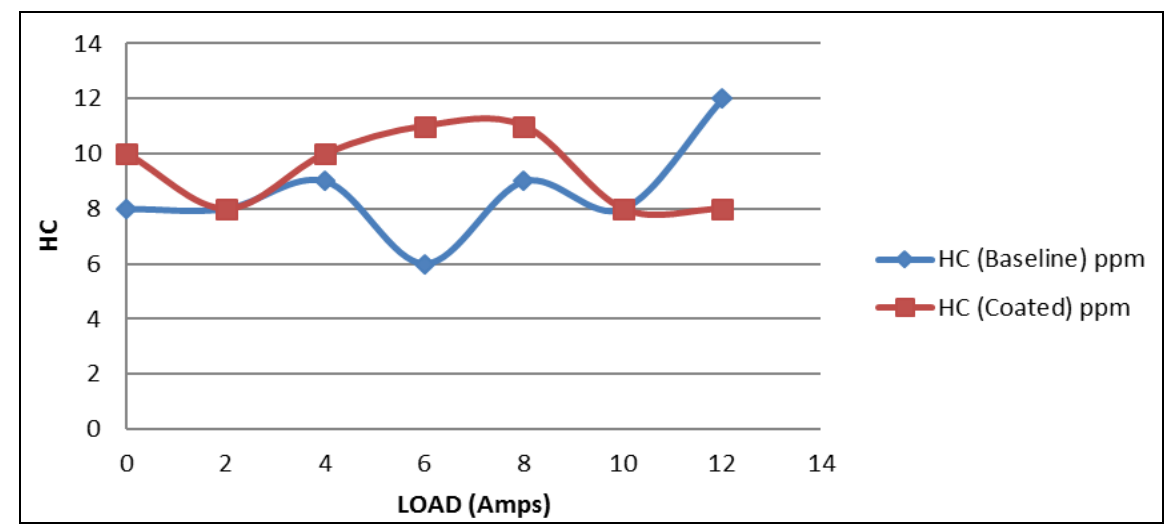

Fig. 11 Load vs UBHC

\section{CO ( CARBON MONOXIDE) EMISSIONS}

In general, it might be expected that the engines would produce less $\mathrm{CO}$, for reasons similar to those for UBHC. In fact, many investigations indicate lower level of $\mathrm{CO}$ emissions $[3,4]$. This is attributed to high gas and combustion walls temperature within the chamber. The present experimental results show that $\mathrm{CO}$ level is increased at lower load and reduced at higher load and indicated in Fig.12. This finding is in line with the variation of UBHC level with load shown in Fig.11. Undoubtedly these coatings function effectively at higher load conditions naturally involving higher temperatures, in the present framework of experimental conditions.

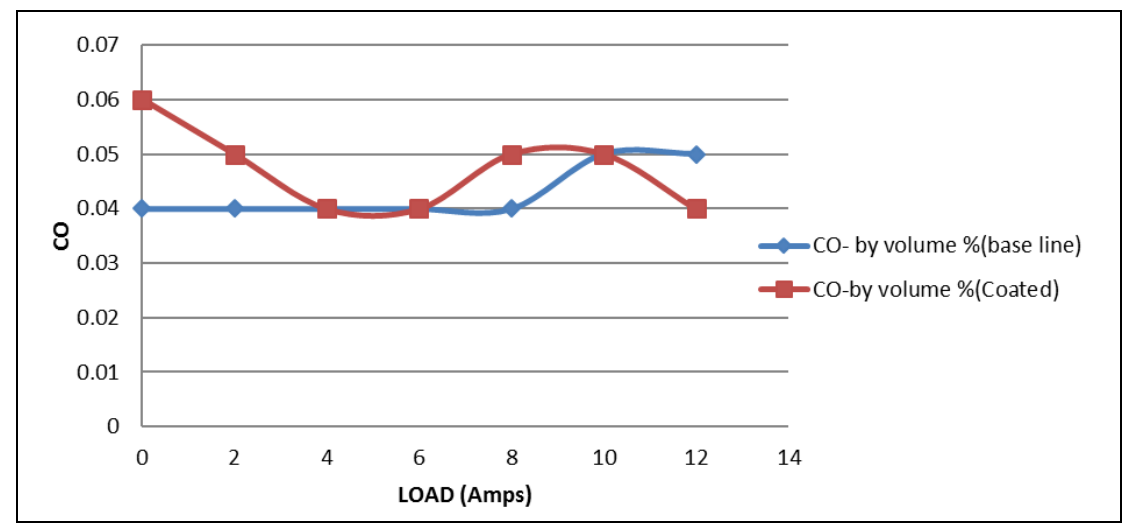

\section{NOx ( NITROGEN OXIDES)}

Fig.12: Load vs CO

NOx is formed by chain reactions involving nitrogen and oxygen in the air. These reactions are highly temperature dependent. Since diesel engines always operate with excess air, $\mathrm{NO}_{\mathrm{X}}$ emissions are mainly a function of gas temperature and residence time. Most of the earlier investigations show that NOx emission from LHR engines is generally higher than that in water cooled engines. This is due to higher combustion temperature and longer combustion duration. Some investigations report an increase in the LHR engine NOx emissions and concluded it is due to the diffusion burning being the controlling factor for the production of NOx. Almost equal number of investigations report declining trend in the level of emission of NOx. This is due to the shortening of the ignition delay that decerases the proportion of the premixed combustion. The present investigations ( Fig. 13) show that NOx level is increased in random when compared to base line. This result is expected considering that the engine used in the present experiment is also 
International Journal of Recent advances in Mechanical Engineering (IJMECH) Vol.5, No.2, May 2016

water cooled and the higher NOx emitted from these type of engines must be controlled by the exhaust system.

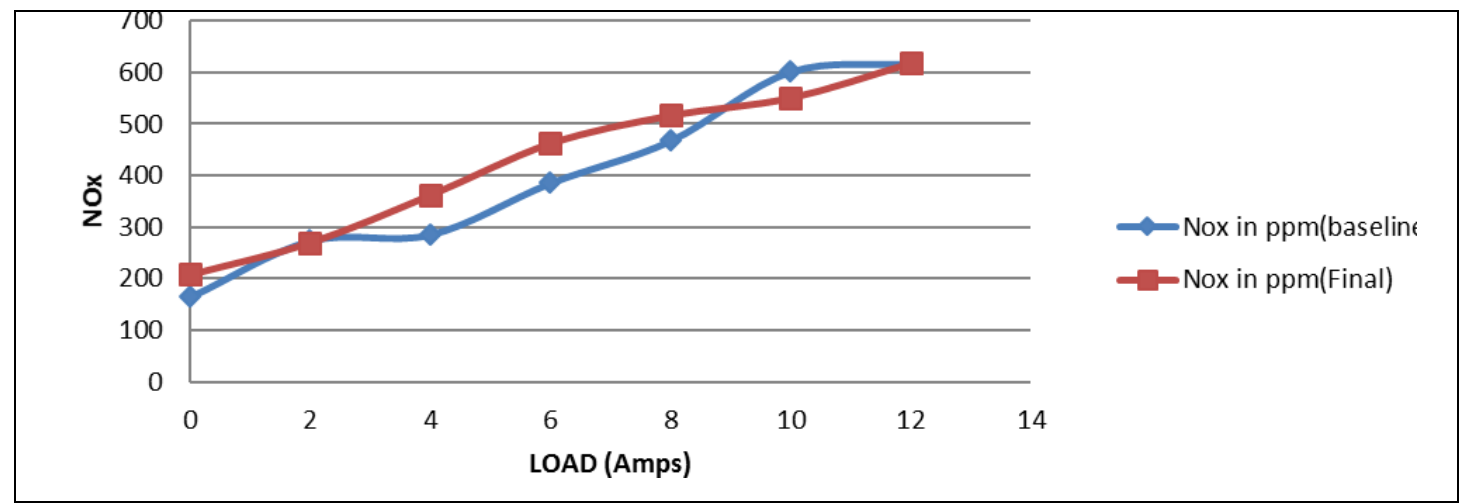

\section{$\mathrm{CO}_{2} \mathrm{AND} \mathrm{O}_{2}$}

Fig. 13 Load vs NOx

It might be expected that LHR engines would produce less smoke and particulates than standard engines for reasons such as high temperature gas and high temperature combustion chamber wall. It is seen that $\mathrm{CO}_{2}$ and $\mathrm{O}_{2}$ and particulates emission level increased in some cases and decreased in a few others. Load vs $\mathrm{CO}_{2}$ and load vs $\mathrm{O}_{2}$ are given in Figs. 14 and 15 respectively.

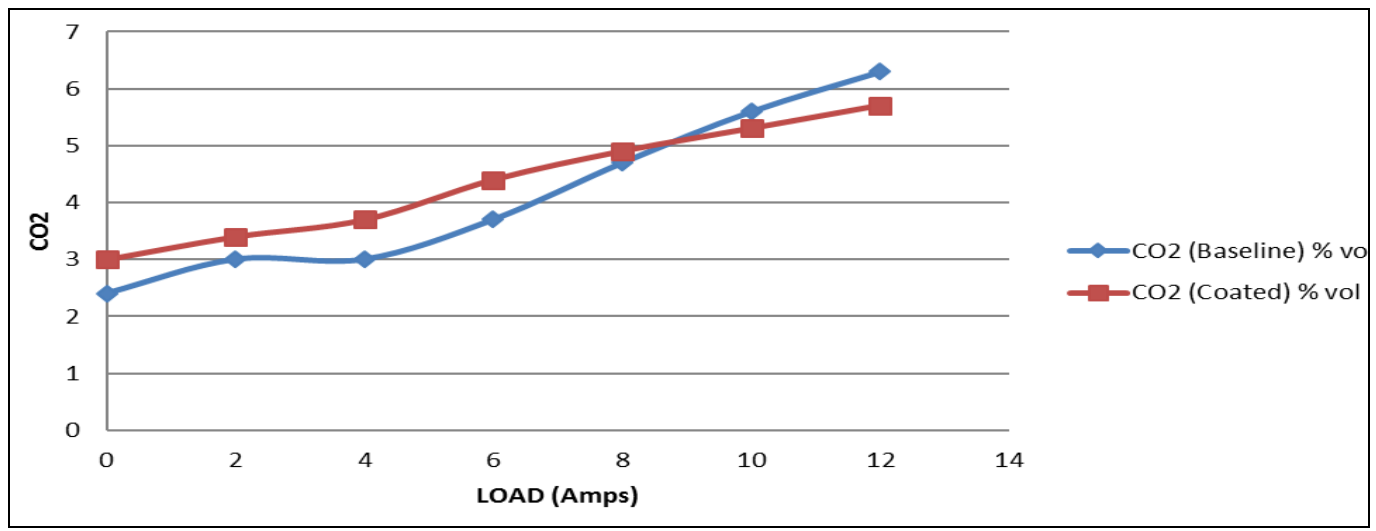

Fig. 14 Load Vs $\mathrm{CO}_{2}$

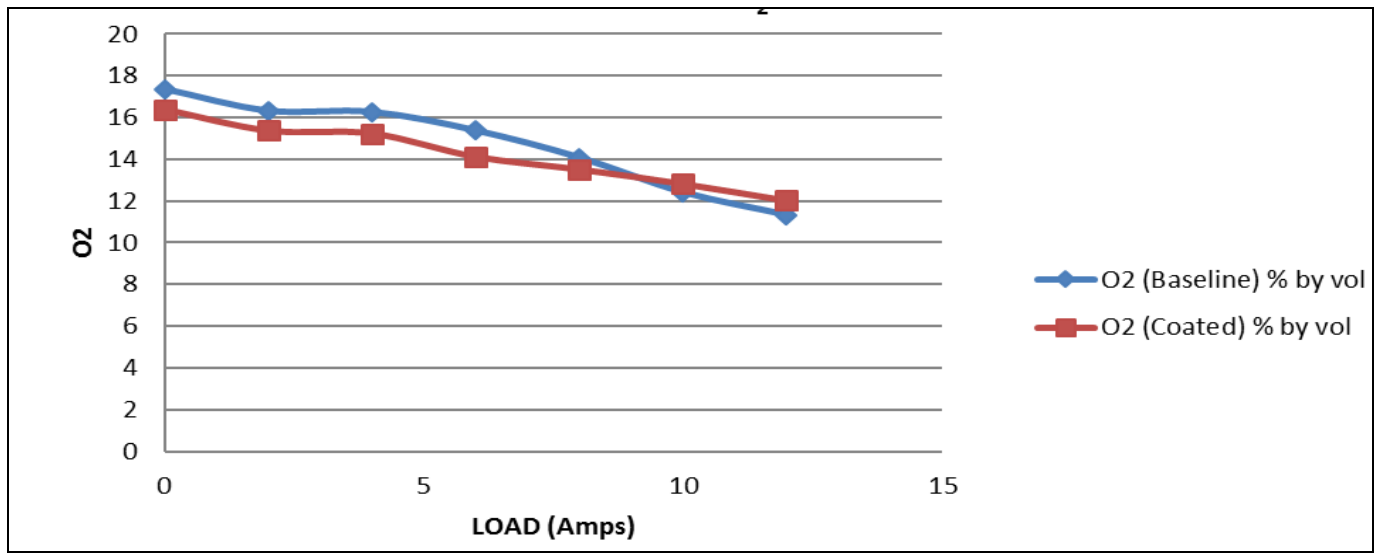

Fig. 15 Load $\mathrm{Vs} \mathrm{O}_{2}$ 
The results obtained show significant reduction in $\mathrm{O}_{2}$ emission and this is due to the enhanced soot oxidation, which is made possible by both the high combustion temperture and the intense turbulence created by the reversed squish. Investigations carried on a smoke analyzer showed increased level of $\mathrm{CO}_{2}$. These two results are perfectly in tandem with each other because the increase in $\mathrm{CO}_{2}$ attributed to soot oxidation is facilitated by the consumption of $\mathrm{O}_{2}$ in the chamber.

\section{(d) Exhaust Gas Temperature}

In an engine with ceramic coated piston, the exhaust gas temperatures are generally higher compared to baseline engine indicating improved combusition in the power stroke. The load vs exhaust gas temperature is indicated in Fig. 16.

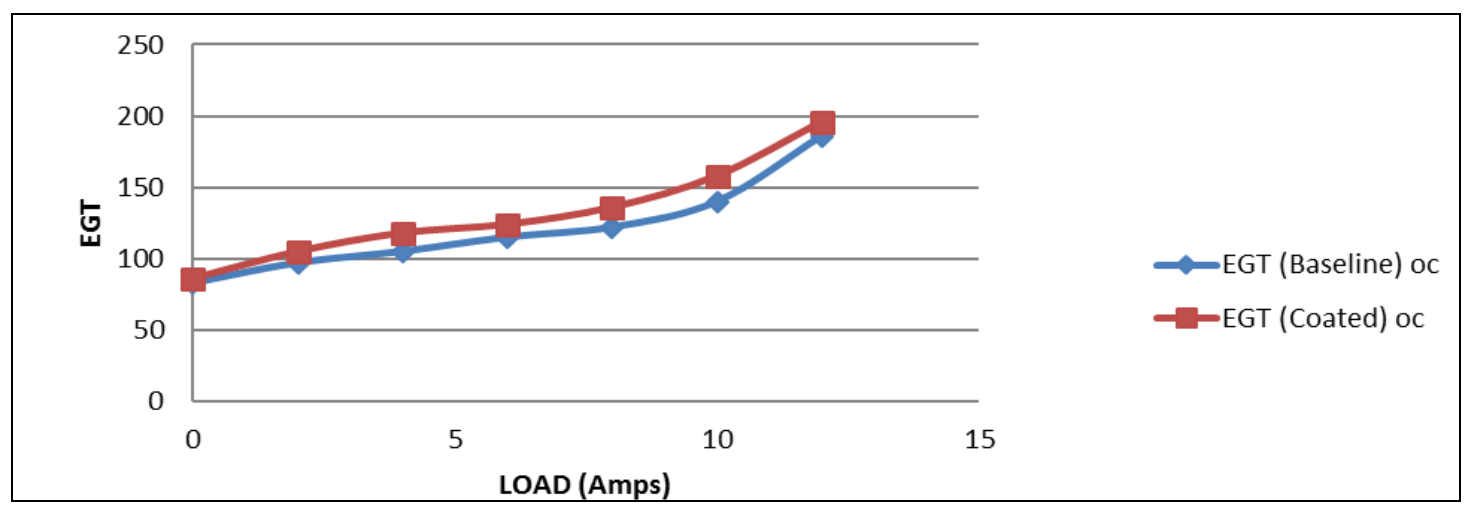

Fig. 16: Load vs Exhaust Gas Temperature

\section{(e) Peak Cylinder Pressure}

Figs. 17 and 18 show the pressure distribution in the engine cylinder, typically at 1550 RPM (Revolutions per Minute) and at varying load conditions from $-180^{\circ}$ to $180^{\circ}$ crank angle, which covers the compression, ignition, combustion and expansion of the charge. Analysis of the data point revealed that the point of all ceramic coated (TBC) piston engine tests is slighlty advanced relative to the engine with uncoated piston tests. The improved ignitability of the fuel-air mixture with reduced ignition delay caused more heat to be released before the TDC ( Top Dead Center) of the cylinders. The combined effect of the continuing compression process and the increased heat release under improved thrmal insulation of piston raised the maximum pressure. As the ignition advanced, there was an increase in the effective expansion stroke that produced the postivie work. 
International Journal of Recent advances in Mechanical Engineering (IJMECH) Vol.5, No.2, May 2016

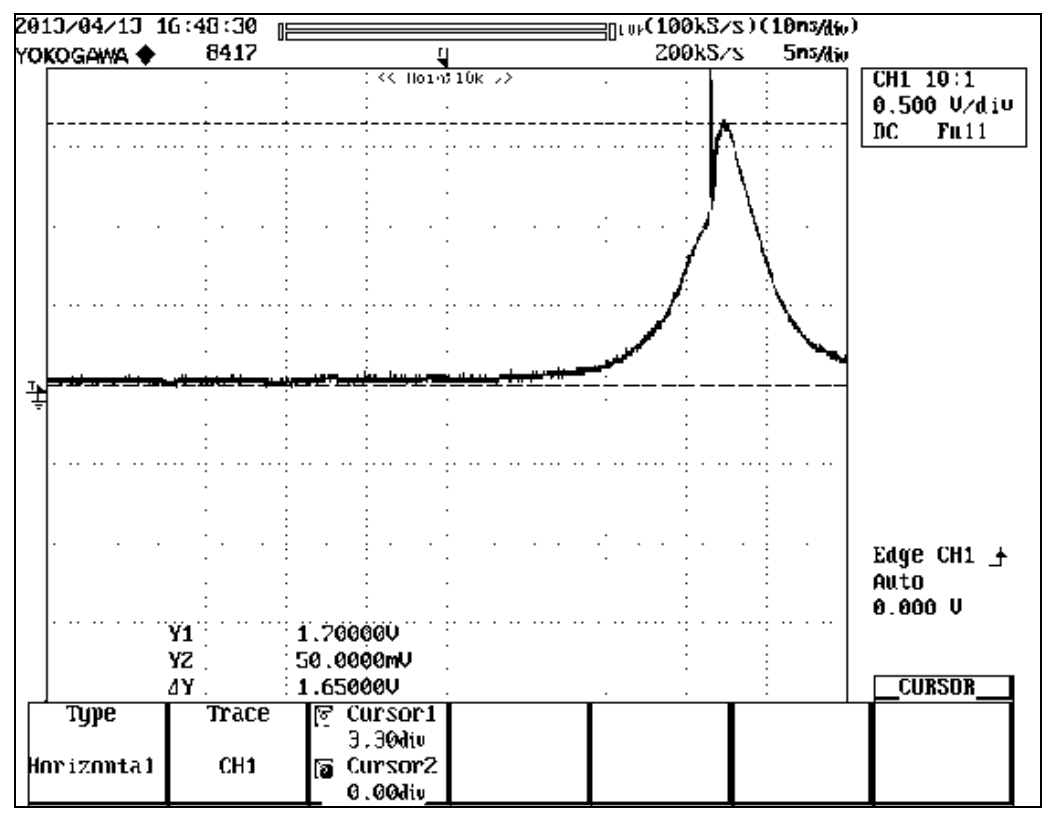

Fig. 17 Peak Pressure before Coating

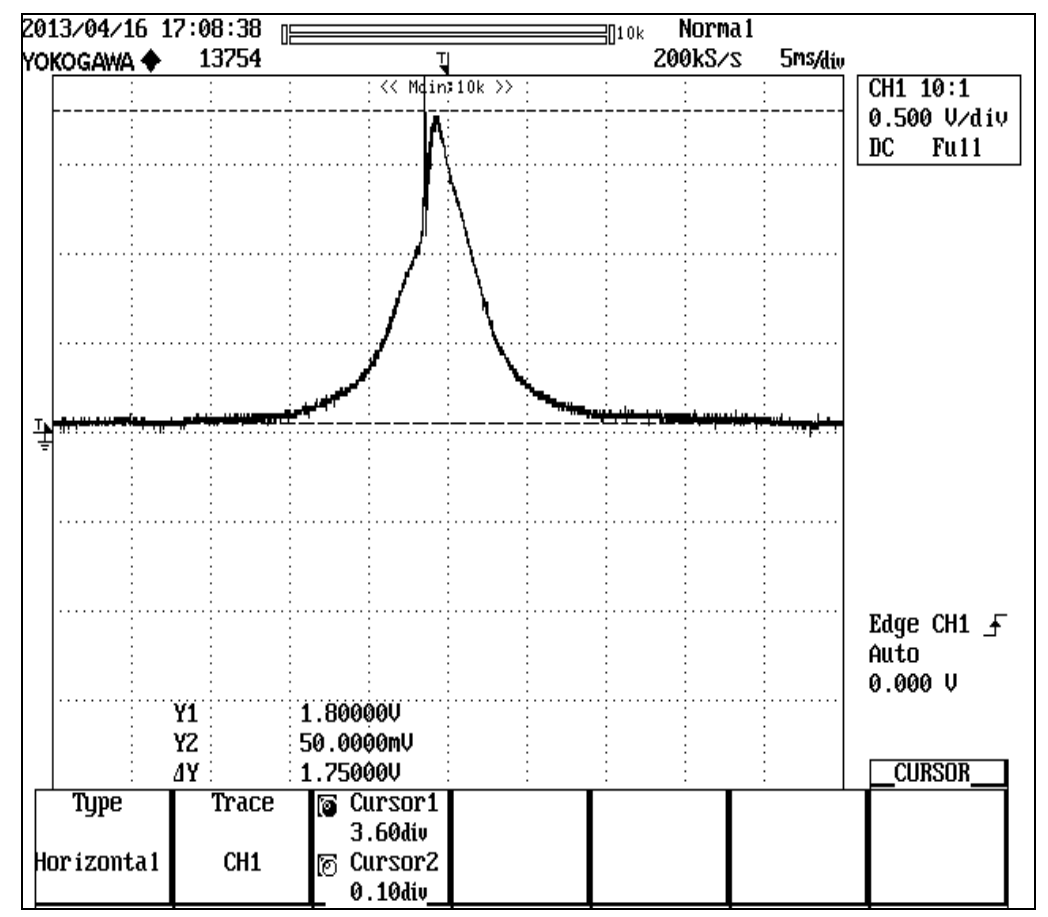

Fig. 18 Peak Pressure after Coating

The positive influence of ceramic coated (TBC) piston in the performance of the engine were evident in the experiments performed: although the maximum extent to which this effect is applicable and observable was not within the scope of this work. 


\section{Conclusions}

In this paper, simulation on TBC coated rectangular substrate and thermal tests are presented. Further, influence of TBC on performance for a single cylinder diesel engine is highlighted. By and large, incorporation of $\mathrm{TBC}$ on the piston crown reduces fuel consumption and offers favorable conditions for reduced pollutants.

Wok is in progress towards coating trials on specially fabricated research piston to finalize the optimum coating parameters and implement LHR concept in four cylinder engine. Adequate number of thermal barrier and thermal shock tests would be carried out on research pistons, prior to the implementation of LHR concept in four cylinder engine.

\section{ACKNOWLEDGEMENTS}

Authors would like to acknowledge with thanks the Christ University Management headed by Vice Chancellor, Dr. (Fr.) Thomas C Mathew, Engineering Director Fr. Benny Thomas, Associate Director (Centre for Research-Projects) Prof. D.N.S Kumar, Associate Dean, Faculty of Engineering Dr. Iven Jose and Mechanical Department Co-Ordinator Dr. Gurumoorthy Hebbar for encouraging R \& D work. Discussions with Dr. Ganesan V., (Retired Professor, IIT Madras) and presently visiting faculty at Christ University are acknowledged. Authors would like to acknowledge with thanks the work on conjugate heat transfer by Mechanical Engineering Department, Assistant Professor and Research Faculty Thejaraju.

\section{REFERENCES}

[[1] Shankar. V, Experimental Studies on Seventy Two Horse Power Class Four Cylinder Diesel Engine, Research Proposal, Report no. CUFE/MRP/001/2013, Christ University, Sep 2013.

[2] D.N.S Kumar, Approval of Major Research Proposal on Experimental Studies on Seventy Two HP Class Four Cylinder Diesel Engine, Nov 2013.

[3] Ilker Turgut Yilmaz, Metin Gumus, Mehmet Akçay, "Thermal Barrier Coatings for Diesel Engines.," International Scientific Conference, Vol.2. pp. 173-177, November 2010.

[4] G. Sivakumar, S. Senthil Kumar, "Investigation on effect of Yttria Stabilized Zirconia coated Piston crown on performance and emission characteristics of a Diesel Engine.," Alexandria Engineering Journal, Vol.54., pp. 787-794, August 2014.

[5] T.M. Yonushonis, "Overview of Thermal Barrier Coatings in Diesel Engines," IEEE Journal of Thermal Spray Technology. Vol.6, pp. 50-56, July 1997.

[6] David R. Clarke, Matthias Oechsner, Nitin P. Padture, "Thermal-barrier coatings for more efficient gas-turbine engines." Materials Research Society Bulletin No.10, Vol.37, pp. 891-898, October 2012.

[7] P. Arjunraj, Dr. M. Subramanian, N. Rathina Prakash, "Analysis and Comparison of Steel Piston over Aluminium Alloy Piston in Four Stroke Multi-cylinder Diesel Engine." International Journal of Emerging Technology and Advanced Engineering, Vol. 5, pp. 116-122, ISSN: 2250-2459, December 2015.

[8] N.Bala Ganesh, T.Senthil Kumar, M.Chandra Sekar "A Review on Thermal Barrier Coating Effects on Diesel Engine performance and emission characteristics" International Conference on Energy Efficient Technologies For Automobiles, Journal of Chemical and Pharmaceutical Sciences ISSN: 0974-2115, 2015.

[9] G. Woschni, W. Spindler, and K. Kolesa, Heat Insulation of Combustion Chamber Walls - A Measure to Decrease the Fuel Consumption of IC Engines, SAE Technical Paper Series, no. 870339, 1987.

[10] Jianguo Zhu, Kang Ma, "Microstructural and mechanical properties of thermal barrier coating at 1400 degree Celsius treatment," The Chinese Society of Theoretical and Applied Mechanics., vol. 4, pp. 15, January 2014.

[11] John B. Heywood, "Internal Combustion Engine Fundamentals." Tata McGraw-Hill 1988.

[12] Ganesan V., "Internal Combustion Engines.” Third Edition, Tata McGraw-Hill, 2007. 
[13] S. J Barnes, K Lades, "The Evolution of aluminium based piston alloys for direct ignition diesel engine, SAE Technical Paper Series", no. 01-0493, 2002.

[14] M.Azadi, M. Baloo et.al., “ A Review of Thermal Barrier Coating Effects on Diesel Engine Performance and Component Life time" International Journal of Automotive Engineering, Vol.3, No. 1, March 2013.pp 305-317.

[15] X.Q. Cao, R. Vassen, and D. Stover, "Ceramic materials for thermal barrier coatings", Journal of European Ceramic Society, Vol. 24, pp.1-10, 2004.

[16] Chan S., H. and Khor K., A. "The effect of thermal barrier coated piston crown on engine characteristics", Journal of Materials Engineering and Performance, Vol.9 (1), pp.103-109, 2000.

[17] G. Sivakumar, V. Shankar et. al, "Is Thermal Barrier Coating for Low Heat Rejection in SI or Diesel Engines", International Journal of Emerging Technologies and Advanced Engineering, Vol. 2, Issue 12, Dec 2012.

[18] Hari et.al, Experimental Studies on Performance Improvements of Eleven HP Class Diesel Engine with Ceramic Coating, B Tech Project Report, Vel Dr. RR \& SR Technical University,Chennai, March 2013.

[19] Kevin Vattappara, Studies on Yttria Stabilized Zirconia as Thermal Barrier Coatings on Metal Substrates, B Tech Project Report, Christ University, Bangalore March 2016.

[20] V. R. Reghu, "Thermal Barrier Coating Development on Piston Crown and Simulation of Low Heat Rejection Engine”, Ph.D. Scholar, Dissertation in Progress, Christ University, Bangalore. 